\section{$\underset{\text { hommes }}{\text { \& migrations }}$}

\section{Hommes \& migrations}

Revue française de référence sur les dynamiques

migratoires

1285 | 2010

L'appel du pied

\title{
Femmes du Caire
}

Film égyptien de Yousry Nasrallah

\section{André Videau}

\section{(2) OpenEdition \\ 1 Journals}

Édition électronique

URL : http://journals.openedition.org/hommesmigrations/1210

DOI : 10.4000/hommesmigrations. 1210

ISSN : 2262-3353

Éditeur

Musée national de l'histoire de l'immigration

Édition imprimée

Date de publication : 1 mai 2010

Pagination : 196

ISSN : 1142-852X

Référence électronique

André Videau, «Femmes du Caire », Hommes \& migrations [En ligne], 1285 | 2010, mis en ligne le 29 mai 2013, consulté le 22 septembre 2020. URL : http://journals.openedition.org/hommesmigrations/ 1210 ; DOI : https://doi.org/10.4000/hommesmigrations.1210

Ce document a été généré automatiquement le 22 septembre 2020.

Tous droits réservés 


\title{
Femmes du Caire
}

\author{
Film égyptien de Yousry Nasrallah
}

\section{André Videau}

1 Longtemps proche collaborateur de Youssef Chahine (Adieu Bonaparte, 1985 ; Alexandrie encore et toujours, 1990 ; Le Caire raconté par Youssef Chahine, 1991), Yousry Nasrallah a su s'imposer comme l'un des réalisateurs majeurs du cinéma égyptien, débusquant, dans une demi-douzaine d'œuvres, les tabous d'une société sclérosée, sans reculer devant les audaces politiques, sociales, sexuelles... L'autre force de ses films, qui leur confère une sorte d'immunité, leur épargnant les foudres d'une censure tatillonne, est qu'ils s'inscrivent dans des trames romanesques conformes aux traditions d'un cinéma oriental souvent sentimental et mélodramatique, qui a toujours eu les faveurs du public. Citons pour mémoire : Vols d'été (1988), film intimiste qui fut une révélation ; À propos des garçons, des filles et du voile (1995), film enquête préparant un cinéma de fresques et de chroniques : La Ville (1999), La Porte du soleil (2004)...

2 Les Femmes du Caire empruntent ainsi des éléments narratifs aux reality-shows et à la presse à sensation, tout en faisant de Heba (Mona Zaki, souveraine du petit comme du grand écran) une captivante disciple de Shéhérazade, l'héroïne mythique des Mille et une nuits, distillant ses "histoires de survie" pour obtenir la clémence du sultan. Dans une trilogie fictionnelle montée comme une série télévisée, les aventures des candidates choisies et de leurs comparses vont se télescoper avec des sujets d'actualité et avec des événements touchant à la vie publique ou privée de la présentatrice.

3 Le succès de l'émission est exceptionnel. Il va bientôt faire planer une menace sur la carrière de Heba. Misogynie ? Jalousie? La classe politique déteste et prend peur. La contestation pourrait être contagieuse. Heba est intraitable mais on pourrait agir sur son mari/amant. Le sémillant Karim (Hassan El Raddad) est un journaliste ambitieux. On lui fait miroiter un possible avancement dans la presse gouvernementale si sa femme change de registre. Cela ne fera qu'envenimer les choses et pourrir le climat conjugal.

4 Le public jouera les arbitres, à la télévision comme au cinéma. Loin de s'offusquer des thèmes audacieux des trois émissions retenues (dont la très sensuelle histoire des trois sœurs célibataires se disputant les faveurs de Saïd (Mohamed Ramadan) commis très 
sexy dans l'exiguïté de l'arrière-boutique de la quincaillerie familiale). Plus ils sentent le soufre, plus les téléspectateurs sont fidèles aux rendez-vous de Heba. Comme par un effet de miroir, et sans doute pour les mêmes motifs, plus de 500000 spectateurs cairotes, bravant l'opprobre officiel, auront vu le film de Yousry Nasrallah qui doit beaucoupà la collaboration de Waheed Ahmed, le brillant scénariste de L'immeuble Yacoubian d'après le roman de Alaa El-Aswany.

Ce film réussi, d'auteurs en renom, est à porter au crédit d'un certain cinéma arabe qui tente, avec le soutien d'un public populaire et cinéphile, d'échapper aux carcans moralisateurs et répressifs. On pourrait citer par exemple Le Fil, film tunisien de Mehdi Ben Attia, avec la vedette icône Claudia Cardinale, qui aborde hardiment l'homosexualité. 